nuclei may be a feeder of messenger to the nucleolus. However, the fully formed nucleolus is usually quite large enough for it to seem plausible that the free diffusion of messenger would be a sufficient mech. anism.

As we see it, the interpretation which has been presented has several advantages. It explains under a single scheme both nucleolar development and function for virtually any form which nucleoli may take, even down to presumable ultrastructural (elementary) nucleoli in lower cells. It does so within a framework where all necessary genes participate. Finally, having regard to the function of messenger RNA, self-priming of messenger as the basis of nucleolar function seems to correspond well with the essentially auxiliary, although in the long run indispensable, general nature of nucleolar function ${ }^{9}$.

It remains to say a word about nucleolar protein. In both the primitive dispersed nucleoli, and in the more evolved consolidated nucleoli, the protein turnover occurs uniformly throughout the whole body of the nucleolus and shows no directional characteristics. In adult cells it occurs mainly during the period of nucleolar growth and is only slight in the fully formed nucleolus. This suggests that the protein synthesis is mainly an aspect of nucleolar growth, and not the production of something like RNA which is contributed to the rest of the cell. In evolved nucleoli some protein could come to the nucleolus in the prenucleolar bodies, and it was actually shown that some of the protein comes from the nucleolus of the previous cell cycle ${ }^{26}$. On the other hand, it might well be that the main synthetic function of the organizer could be the early production of an organizing nucleolar protein ${ }^{24}$. This is perhaps suggested by the topographical relationships between the organizer and the dense particulate region mentioned above. It should also be noted that in cleanly isolated nucleoli there is only one major protein ${ }^{27}$. It has been suggested that the nucleolus synthesizes ribosomal protein ${ }^{28}$. If so, this protein would presumably have to be made in the many dispersed elementary nucleoli in the less-evolved stage. This possibility cannot be ruled out, but, since ribosomal protein has a similar overall composition in all species examined, the suggestion that many different genes all make essentially the same ribosomal protein does not appear to us very attractive. Our view ${ }^{24}$ is that the nucleolus (and possibly the nucleus as a whole) essentially contributes free informational RNA's and does not contribute protein, which is made outside the nucleus and possibly by the ribosomes themselves. Evidence for this comes from the free state of messenger ${ }^{12}$ and, possibly, from ribosome reorganization during regeneration ${ }^{24}$.

We thank Prof. C. H. Waddington for help in preparing the manuscript.

This work is supported by the Damon Runyon Memorial Fund for Cancer Research (DRG-579).

${ }^{1}$ Sirlin, J. L., Kato, K.-I., and Jones, K. W., Biochim, Biophys A 48, 421 (1961).

${ }^{2}$ Vincent, W. S., and Baltus, E., Biol. Bull., 119, 299 (1960).

'Sibatani, A., de Kloet, S. R., Allfrey, V. G., and Mirsky, A. E.,

- Vincent, W. S., Science, 126, 306 (1957).

- Hurwitz, J., Furth, J. J., Anders, M., Ortiz, P. J., and August, J.T., J.Chim. Phys., 58,934 (1961); and personal communication. Rauen, H. M., Kersten, H., and Kersten, W., Z. Phys. Chem., 321, 319 (1960). Harbers, E., and Müller, W., Biochem. Biophys. Res. Commun., 7, 107 (1962). Goldberg, I. H., and Rabinowitz, M., Science, 136, 315 (1962).

- Sirlin, J. L., Jacob, J., and Kato, K.-I., Exp. Cell. Res. (in the press) ${ }^{7}$ Allfrey, V. G., Mirsky, A. F., and Osawa, S., J. Gen. Physiol., 40, 459 (1957).

'Allfrey, V. G., and Mirsky, A. E., Proc. U.S. Nat. Acad. Sci., 43,

- Sirlin, J. L., Prog. Bioph. Biophys. Chem., 12, 25 (1962).

${ }^{10}$ Sirlin, J. L., Jacob, J., and Kato, K.-I. (unpublished observations).

'Perry, R. P., and Dürwald, H., Abstr. Biophys. Soc., Sixth Ann. Meet., Washington (1962).

12 Gros, F., Naono, S., Hayes, D., Hayes, F., and Watson, J. D., Colloque International sur les Acides Ribonuclétques (C.N.R.S.', Strasbourg, in the press). Otaka, E., Osawa, S., and Oota, Y., T. Mol. Biol., 3, 693 (1961). Hotta, Y., Osawa, S., and Sakaki,

Jacob, J., and Sirlin, J. L. (in preparation).

Sirlin, J. L., and Schor, N. A., Exp. Cell. Res. (in the press).

Goldstein, L., and Micou, J., J. Biophys. Biochem. Cytol., 6, 301 (1959). Woods, P. S., Brookhaven Symp. Biol., 12, 253 (1959). Feinendegen, L. E., Bond, V. P., Shreeve, W. W., and Painter,

${ }^{16}$ Perry, R. P., Hell, A., and Errera, M., Biochim. Biophys. Acta, 49, 47 (1961); 49, 58 (1961)

${ }^{17}$ Vincent, W. S., The Beginnings of Embryonic Development, 1 (Amer. Assoc. Adv. Sci., Washington, 1957).

${ }^{18}$ Kitazume, Y., Yras, M., and Vincent, W. S., Proc, U.S. Nat. Acad. Sci., 48, 265 (1962). 'Speyer, J. F., Lengyel, P., Basilio, I., and Ochoa, S., Proc. U.S.
Nat. Acad. Sci., 48, 441 (1962).

${ }^{20}$ Allfrey, V. G., and Mirsky, A. E., Proc. U.S. Nat. Acad. Sci., 45, $1325(1959)$

${ }^{21}$ O'Brien, B. R. A., J. Embryol. Exp. Morph., 9, 202 (1961).

${ }^{22}$ Goldberg, I. H., and Rabinowitz, M., Biochem. Biophys. Res. Commun., 6, 394 (1961). Hartmann, G., and Coy, U., Z. Physiol. Chem., 328, 285 (1961)

${ }^{23}$ Hoagland, M. B., Nucleic Acids, 3, 349 (1960).

${ }^{24}$ Sirlin, J. L., Intern. Rev. Cytol. (in the press).

${ }^{25}$ Tandler, C. J., and Sirlin, J. L., Biochim. Biophys, Acta, 55, 228 (1962). ${ }^{26}$ Harris, H., Nature, 190, 1077 (1961). Martin, P. G., ibid., 1078

${ }^{27}$ Vincent, W. S., New Approaches in Cell Biology, 89 (Academic Press, London, 1960)

28 Bonner, J., Protein Riosynthesis, 323 (Academic Press, London,
1960).

\title{
THE LOWER ARCHEGONIATE PLANTS
}

$\mathrm{O}$ VER the years the Linnean Society of London has had many important meetings and discussions to its credit. The recent symposium on "The Growth and Development of the Lower Archegoniate Plants", held in the Society's rooms during April 5-6, had, however, the unique distinction, as the president, Prof. T. M. Harris, stated in his opening remarks, of being the first truly international symposium ever arranged by the Society. In addition to British representatives, the speakers included botanists from Canada, the United States, France, Germany and Finland, and, in all, sixteen papers were read. About one hundred people attended each of the four sessions. In passing, it may perhaps be noted that a group of this size proved admirable for the progressive development of full and friendly discussions.

In opening the first session (over which Prof. Harris presided) on the gametophyte, Mr. P. R. Bell (University College, London), to whom much credit for arranging the symposium is due, referred to the value of ferns and mosses for studies of growth, development and differentiation. $\mathrm{H}_{\theta}$ indicated that classical problems of long standing concerning the differences between the altornating phases of the life-cycle might perhaps be solved by the application 
of new techniques; and he affirmed that principles of cellular biology based on the lower archegoniate plants could have important applications to higher plants. Prof. H. Mohr (Botanisches Institut, University of Freiburg, West Germany) then submitted observations on the influence of visible radiation on the germination of spores of archegoniate plants, in particular of Dryopteris filix-mas, Funaria hygrometrica and Sphaerocarpus sp., and on protonemal growth. These and other investigations indicate clearly the importance of light and of photoreactive systems in growth and morphogenesis. Spore germination in $F$. hygrometrica, for example, is controlled by light, though the processes involved are complex. The first stage of germination, involving the uptake of water, enlargement, rupture of the exospore and conspicuous greening of the plastids, can occur in darkness in some of the spores of a population. The results so far obtained indicate that the control of this stage is mediated by the phytochrome system. The second stage, which includes the outgrowth of the rhizoid and/or chloronema, is also controlled by light, photosynthesis being involved. The spores of Sphaerocarpus are obligate light germinators, at least two photoreactive systems being involved.

Since germination can be induced by both blue and far-red radiation, it is tentatively assumed that there is a promotive photoreactive system identical with the blue, far-red reaction system (the so-called 'high energy reaction of photomorphogenesis'). The inhibiting reaction system, which is particularly effective with longer daily periods of irradiation, may be identical with the phytochrome system.

In Dryopteris filix-mas, the relative and absolute protein contents of blue-grown prothalli increase much more than do the protein contents of the corresponding red-grown filaments (protonemata), even when the increase in dry weight is about the same under both light conditions. After a transient increase the relative protein content remains constant in darkness and in red light, whereas in blue light the relative protein content increases steadily, at least during the experimental period. If red-grown protonemata are placed under blue light and bluegrown prothalli under red light, rapid shifts in the relative protein contents are observed, indicating that, in a gametophyte, the protein content is actively brought to a certain level determined by light wave-length. It thus appears that the increased rate of protein synthesis in blue light is intimately connected with the related critical developmental changes. It is probable that photomorphogenetic light reactions determine into which metabolic pathways the primary products of photosynthesis are channelled. In the plants under consideration, a photoreactive system which depends on blue light apparently directs this flow of metabolites primarily in the direction of protein synthesis.

Prof, A. Vaarama (in collaboration with Niina Tarén, University of Turku, Finland) gave an account of the synergism of calcium and certain growth substances in the germination and protonemal growth of mosses, based on their experimental studies of certain lithophytic and non-lithophytic calcicolous species and a calciphobous species. Among other observations, gibberellic acid inhibited protonemal growth in all the calcicolous species tested, but promoted growth in Dicranella cerviculata, a calciphobe.

Prof. M. Bopp (Botanisches Institut, University of Freiburg, West Germany) discussed differentiation in moss protonemata and the factors controlling bud formation in them. During the development of the protonema of Fumaria hygrometrica, two different substances diffuse into the substrate. In the chloronema a heat-labile, growth-promoting substance is formed; in the caulonema, after about ten days, a heat-stable substance, soluble in amyl alcohol, is formed. This substance functions as a growth inhibitor. Both substances affect bud formation, which is at an optimum only when a certain balance between them exists. This bud-inducing effect is fundamentally different from that due to kinetin, in that the latter only functions as an additional factor in promoting bud formation. Kinetin is regarded as an agent which creates centres of activity toward which morphogenetic substances are drawn. This view is supported by the facts that kinetin cannot be transported and therefore has no 'after-effect' and that it functions only when it penetrates a caulonema cell. It converts every caulonema cell into a 'reaction cell'. The opening session was completed by a contribution by three French workers, Messrs. Kofler, Dutel and Nurit, on variations in the geotropic sensitivity of germinating Funaria spores in response to external factors such as light, and to applied growth substances, glucose, etc. (This paper was read by Dr. E. Lodge.)

The second session (under the chairmanship of Prof. C. W. Wardlaw, University of Manchester) was mainly devoted to factors which affect the formation of antheridia. Dr. U. Näf (Rockefeller Institute, New York) dealt with an antheridium-inducing effect of a specific substance which is apparently common to many polypodiaceous ferns, though it is inactive when applied to some Schizaeaceae, Osmundaceae and Cyatheaceae.

The prothalli of Onoclea sensibilis respond to the active substances at an early stage of development but become incompetent to respond to it soon after they attain the adult heart-shape. This loss of sensitivity occurs within less than two days. Once they have become insensitive, prothalli fail to respond to the active substance even if they are supplied with very high concentrations, for example, 15,000 times higher than that which is sufficient to bring about a response in prothalli just two days younger. Surgical studies by Dopp have shown that the meristem of the maturing prothallus begins to form a substance to which the loss of sensitivity can be attributed. Dr. Näf suggested that the antheridial factor acts by modifying a situation which blocks or inhibits antheridium formation. In the course of a lively and entertaining discussion of this paper-to give one indication of the mood of the symposium-it emerged that the responses of antheridia in the common bracken, Pteridium aquilinum, were considerably different on the two sides of the Atlantic-varietal effects being no doubt involved.

Dr. D. Wilkie (University College, London) then varied the general tenor of the session by giving an account of a genetical analysis of bracken (Pteridium aquilinum) prothalli. In the course of this work, based on the pure culture of single spores, he frequently observed a form of prothallus lacking a meristem. Actually, some 20 per cent of the spores yielded these small, ameristic prothalli; they bore antheridia and most of them usually reverted to normal forms. The genetical properties of these variant forms were investigated by methods involving cross- and self-fertilization analysis. A genetic analysis of the spores from the resulting sporophytes 
showed that control of the ameristic character could not be directly attributed to the action of nuclear genes. Accordingly, a hypothesis of heritable cyto. plasmic units was advanced to explain the results.

The session was concluded by a paper from Prof. L. Bauer (Botanisches Institut, University of Tubingen, West Germany) on his experiments on the stabilizing of the male sexual tendency in mosses, Splachnum sp., that is, by the repression or exclusion of the female tendency by exposing plants to certain external conditions. The persisting modifications which he obtained were attributed to cytoplasmic factors.

In the third session (under the chairmanship of Prof. L. J. Audus, University of London) the speakers were mainly concerned with the further differentiation of the protonema and prothallus and their products, especially as it related to the sporogonium in mosses and the ovum and young embryo in ferns. Prof. Bauer made a very interesting contribution on the physiology and organization of sporogonium differentiation in mosses. He demonstrated that if different regions, apical, sub-apical and maturing, of the distal part of the young needle-like sporophyte were isolated and cultured, they typically gave rise to different morphological entities. The more distal segments were capable of regenerative growth and eventually gave rise to sporogonia, but the more proximal maturing segments had apparently lost permanently some of their initial inherent potency and did not give rise to sporogonia when cultured under the same conditions as the other segments. This observation in mosses appears to be in general accord with contemporary eytogenetical conclusions based on work in other groups.

Mr. P. R. Bell (University College, London) then gave an account of recent work on the cytochemical and ultrastructural peculiarities of the unfertilized egg in Pteridium aquilinum. His lecture was illustrated by some excellent electron micrographs which not only shed new light on a classical botanical topic but also on fine-structural features of the nucleus and cytoplasm. Critical observations on staining and cytochemistry were followed by an account of some novel observations on the nucleus and cytoplasm as disclosed by electron microscopy. As the egg matures the nucleus appears to evaginate into the cytoplasm and there is evidence that, in the formation of the egg, the plastids and mitochondria derived from those of the gametophyte degenerate. The mature egg, in fact, contains a new set of mitochondria, the evidence so far obtained from this material suggesting that they may be formed with the direct participation of the nucleus. Although it has not yet been possible to correlate the peculiar cytochemistry of the egg with its unique ultrastructure, Mr. Bell suggested that the evidence now accumulating admitted of the interpretation that the mature egg has a cytoplasm which is transformed under the influence of the nucleus; and this he considered may be responsible for the differences in complexity of the morphological configuration generated by the spore and the zygote.

Dr. A. E. De Maggio (Rutgers University, New Jersey) introduced the theme of the developing sporophyte by giving an account of morphogenetic factors which affect the development of the fern embryo. In particular, he illustrated and discussed the effect of the physical restraint which may be exercised on the developing zygote by the archegonial wall and adjacent gametophyte tissues, and the effects of nutritional factors. His surgical experiments showed that the early, complete removal of the natural, restrictive limitations imposed on the zygote and growing embryo seriously affects the potentiality of the young sporophyte for three-dimensional growth and normal sporophyte production. Whether this single modification, which leads to what looks like a reversal of the regular phases in the alternation of generations, results in a loss of control over the planes of cell division, as previously suggested, or deprives the embryo of essential growth substances necessary for orderly sporophyte formation, remains to be seen. In the species studied it is known that changes in carbohydrate nutrition do not account for permanent alterations in the morphological form. Accordingly, the possibility cannot be overlooked that nutritional and hormonal interactions can give rise to changes in embryo development of such a magnitude as to suggest that these substances exert considerable control in determining morphological levels of development.

These explorations of factors in the early embryo. genesis in ferns were taken a stage further by Dr. M. Ward (Glenville State College, West Virginia), who discussed developmental patterns in adventitious, that is, non-sexual, sporophytes of Phlebodium aureum. Such sporophytes are regularly formed when petiole and rhizome segments are grown in various culture media. Gametophytic plants regularly develop from petiole segments but sporophytic plants are less common. On rhizome sections in culture, sporophytic and gametophytic forms occur at random and often adjacent to each other. Apogamous sporophytes thus formed tend to give rise to secondary apogamous sporophytes on their own leaves. In this fern, apogamous sporophytes are also regularly formed on the normal gametophyte under appropriate cultural conditions.

The genetic constitution of these apogamous and aposporous forms has not yet been established. Certain problems incident to the classical cycle of alternation of generations are indicated by the occur. rence of these adventitious plants. This session was concluded by an outline account of leaf regeneration in Adiantum pedatum given by Dr. G. Morel (Institute of Plant Physiology, Versailles). Since, in this fern species, juvenile leaves regenerate gametophytes, whereas adult leaves regenerate sporophytes, it may be inferred that during the process of ageing the factor controlling gametophyte formation, still present in juvenile leaves, tends to be lost. If this be accepted, the problem is to ascertain how the same nucleus controls the development of these very different morphological entities-the small cordate laminæ with sex organs, and the sporophytic plant with roots and spore-bearing leaves, respectively. In each, the information coded in the chromosomes should be the same but, nevertheless, the resulting organisms show marked differences in their morphology.

The fourth and final session was held under the chairmanship of Dr. C. R. Metcalfe (Royal Botanical Gardens, Kew), botanical secretary to the Linnean Society, who also had an important share in the arrangement of the symposium. In an account of apical organization and allometric growth in ferns, Prof. C. W. Wardlaw illustrated, by reference to a number of common British and some exotic ferns, that the main organizational features of the developing sporophyte of any particular fern, and much of the morphological diversity in ferns in general, can be referred (1) to the inception of a characteristic primary pattern of organs in the apical meristems of 
shoot and leaves, and (2) to various elaborations of these patterns by differential or allometric growth in the sub-apical and maturing regions.

Factors of various kinds, genetical, nutritional, correlative and environmental, may, in different instances, affect the primary pattern and the nature of differential growth. Accordingly, the view was advanced that the phenomena of organization in plants lend themselves to analytical and experimontal investigation, but synthesis is evidently an essential part of the task.

Dr. T. A. Steeves (University of Saskatchewan) then contributed a detailed analysis of the growth and morphogenesis of the leaf of Osmunda cinnamomea, dealing first with the inception and developinent of the circinately-coiled primordium and of the maturing but still rolled leaf, and then with the further physiological activities which result in the uncoiling of the more or less adult leaf in spring. Particular attention was given to the relative roles of cell division and cell elongation in the ground tissue of the leaf rachis throughout development. The coiled condition of the rachis in the crozicr was interpreted as the result of more cell division abaxially than adaxially during its formation, and uncoiling depends on the equalizing of cell numbers by cell division late in leaf development. Cell elongation in $O$. cinnamomea, except in the leaf base, is delayed until the fifth growing season, at which time it extends acropotally along the rachis. Leaf elongation in several ferns depends on diffusible auxin, probably indolylacetic acid, from the pinnæ. Leaf primordia, after being determined, can complete thoir development in isolation in sterile nutrient culture, indicating that the essential features of leaf formation are regulated within the organ itself. The small size of cultured leaves is the result of diminished cell division in the rachis and appears to have a nutritional basis.

Finally, in this session, Dr. A. Allsopp (University of Manchester) summarized and illustrated his many experimental investigations of morphogenesis in Marsilea spp., using aseptic culture technique. Special attention was given to the effects of nutri- tional factors and growth-regulating substances in heteroblastic development and other organizational features, and to the physiological conditions which determine the characteristic features of land and water forms. He concluded that the changes in leaf segmentation of Marsilea, or heteroblastic develop. ment, are correlated with changes in the size of the apical meristematic regions of the shoot, which in turn are influenced by the nutritional status of the plant. On the other hand, the differences between land and water forms are probably due to differences in tho available concentration of dissolved carbohydrates in the growing parts.

When I reflect on the symposium as a whole, my thoughts naturally turn to Hofmeister, Goebel, Campbell, Bower and Lang, and to the many other distinguished botanists of past times who contributed so much to our knowledge of the growth and morphology of archegoniate plants, and, not least, who were so profoundly interested in the causes underlying their singularly unlike alternating genorations. Had the shades of those eminent ones lingered awhile on this occasion, they might well have been stirred to surprise and wonder at the interest these plants and their problems still command; and, liko myself, at the end of the meeting, they might perhaps have entertained the optimistic view that, although we evidently still have a very long way to go, wo are at length coming within tangible distance of a more factual interpretation of some aspects of the growth, morphology and life-cycle of these enigmatic and fascinating plants. Accordingly, this is a suitable place to express the appreciation of all who participated in these sessions to the president and officers of the Linnoan Society for arranging the symposium, and to the British Council and the International Union of Biological Sciences for very substantial financial assistance, without which, indeed, the symposium could not have been held.

The papers contributed will be published collectively as a number of the Journal of the Linnean Society as soon as possible and this may be obtained from the Society.

C. W. WARDLAW

\section{O BITUARIES}

\section{Dr. L. G. G. Warne}

The University of Manchester has lost a valued member of staff in the sudden death of Leslie Gordon Glynn Warne on May 3, agod fifty-three years. $\mathrm{He}$ had suffered a severe coronary thrombosis in 1955, which slowed his movements somewhat; he was well aware of a possible fatal recurrence, but he rotainod full mental vigour, wonderful personal equanimity, and continued his university activities as senior lecturer in horticulture and assistant director of the Experimental Grounds. Actually, he was engaged on field work at the experimental grounds of the University, Jodrell Bank, Cheshire, when he collapsed.

Warno was born at Faringdon, Berks., on June 25 , 1908. On leaving St. George's Secondary School, Bristol, he was employed for three ycars in investigational work in the laboratory of Messrs. H. J. Packor and Co., Ltd., cocoa and chocolate manufac:turers. In 1928 he entered the University of Bristol, and in 1932 he graduated with first-class honours in botany. In 1933 he was awarded M.Sc. and in 1936 Ph.D. He joined the staff of the University of Manchester in 1934 as assistant lecturer in botany, served the Department in many ways and was appointed senior lecturer in horticulture in 1948. This is an endowed post, the aim of which is to help gardeners and others to secure adequate scientific and professional training and to encourage horticulture in the region. Warne had a considerable share in organizing the Experimental Grounds and evening classes in botany and horticulture in this connexion. Indeed, his gifts as an organizer and as a practical gardener not only equipped him for this work and brought him succoss, but were also a great asset to the Department.

In 1953 the University granted him three years leavo of absenco to occupy the chair of botany at Karachi, Pakistan. There his varied ability again bore fruit, and his keenness and energy enabled him to acquaint himself with the work of other institutess in Pakistan and India, and to become familiar with tropical vegetation and agriculture. 